Research Article

\title{
Spiritual Well-Being among Medical and Nonmedical Science Students
}

\author{
Mahboobeh Maazallahi (D), ${ }^{1}$ Asma Ghonchepour $\left(\mathbb{D},{ }^{1}\right.$ Mostafa Sohrabi ${ }^{1}{ }^{2}$ \\ Zakiyeh Golestani $\mathbb{D}^{1},{ }^{1}$ Peiman Parandeh Afshar $\mathbb{D}^{1},{ }^{1}$ Alireza Malakoutikhah $(\mathbb{D}){ }^{1}$ \\ and Mahlagha Dehghan $\mathbb{D}^{3}$ \\ ${ }^{1}$ Student Research Committee, School of Nursing and Midwifery, Kerman University of Medical Sciences, Kerman, Iran \\ ${ }^{2}$ Shiraz University of Medical Sciences, Shiraz, Iran \\ ${ }^{3}$ Nursing Research Center, Kerman University of Medical Sciences, Kerman, Iran \\ Correspondence should be addressed to Mahlagha Dehghan; m_dehghan@kmu.ac.ir
}

Received 20 December 2020; Revised 27 March 2021; Accepted 17 April 2021; Published 26 April 2021

Academic Editor: Vance Zemon

Copyright ( 92021 Mahboobeh Maazallahi et al. This is an open access article distributed under the Creative Commons Attribution License, which permits unrestricted use, distribution, and reproduction in any medium, provided the original work is properly cited.

\begin{abstract}
Spiritual well-being is one dimension of health that provides a person with stability, meaning, fulfillment in life, and self-belief. This study aimed to compare the spiritual well-being among students of Kerman University of Medical Sciences and the Shahid Bahonar University of Kerman. With the demographic questionnaire and 20-item spiritual well-being scale of the "Paloutzian and Ellison" questionnaire, a cross-sectional study was conducted on 626 students of the universities of medical and nonmedical sciences by the quota sampling method in Kerman in 2017-2018. The scores of spiritual well-being and its two components were significantly higher in nonmedical science students $(89.83 \pm 16.79)$ than in the medical science students $(81.61 \pm 15.21)(p<0.05)$. In addition, one percent of the nonmedical science students had a low level, $67.7 \%$ had a moderate level, and $31.3 \%$ had a high level of spiritual well-being. $0.3 \%$ of the medical science students had a low level, $84 \%$ had a moderate level, and $15.7 \%$ had a high level of spiritual well-being. Since spirituality is important for the profession of medical science students, it may be necessary to expand this component in their curriculum.
\end{abstract}

\section{Introduction}

University students are at a critical period in their lives that is characterized by individuation and separation from family, development of new social connections, and increased autonomy and responsibility [1]. People in this period face new challenges in education, social relationships, and other fields. These changes lead to increased levels of stress and adaptive and behavioral problems that can adversely impact their health [2, 3]. Spiritual well-being is considered as a psychological resource of coping that reduces suffering and leads people to consider traumatic situations or disturbing events from a positive perspective $[4,5]$. Although health has been defined based on three physical, mental, and social dimensions for decades, Russell and Osman included the spiritual dimension in the definition of health [6].
Spiritual well-being is a unique source that coordinates physical, mental, and social dimensions, and it is characterized by stability in life, peace, adjustment, and harmony, a sense of close relationship with oneself, God, society, and the environment [7]. Spiritual well-being consists of two components of religious well-being and existential wellbeing. Religious well-being is a sign of communication with God, and existential well-being is the sense of purpose in life, peace, and life satisfaction [8]. Spiritual well-being had an effect on the physical, social, and psychological aspects of an individual's life [9]. University students in this period of life take more responsibility for their health and have greater control over their lifestyle than adolescents. Lifestyle changes can have strong implications on their health and well-being [3]. Furthermore, mental health among university students could be affected by spiritual well-being [10]. 
Various studies investigated the spiritual well-being of university students. Feizi et al. found that healthcare students had moderate spiritual well-being and showed a positive correlation between happiness and spiritual wellbeing among healthcare students [11]. Moreover, Alorani and Alradaydeh demonstrated a negative correlation between spiritual well-being, depression, and aggression [8]. Fabbris et al. indicated a significant association between well-being and reduced anxiety levels in nursing students [5]. Mehri et al. found a significant relationship between spiritual well-being and health-promoting behaviors [12]. Moreover, one study in Jordan (2015) showed an association between spiritual well-being and better college adjustment among university students [13]. Abdel-Khalek showed a significant and positive correlation between spiritual wellbeing and quality of life [14].

The transition from adolescence to the youth period causes young people to face sensitive and critical situations. Concerning the role of spiritual well-being in improving the mental and physical well-being of individuals, it is necessary to improve the spiritual well-being of young people, especially students. Since medical science students and nonmedical science students have different talents and educational backgrounds, and medical science students are expected to be aware of and practice healthy behaviors [3], it is necessary to study their spiritual wellbeing separately to design and implement different interventions in each of the universities. Therefore, this study aimed to compare the students' spiritual well-being in two Kerman universities of medical sciences and nonmedical sciences.

\section{Materials and Methods}

2.1. Study Design and Setting. This comparative cross-sectional study was conducted during the academic year of 2017-2018. All students of Kerman University of Medical Sciences and Shahid Bahonar University of Kerman, Iran, were invited to take part in the study. Kerman is the largest city in the southeast of Iran, which is located in Southwest Asia. There are two central governmental universities in Kerman (Kerman University of Medical Sciences and Shahid Bahonar University of Sciences). In the academic year of 2017-2018, 19089 students were studying in different majors and degrees in these universities. In addition, in Iran, all students in medical and nonmedical universities must pass nearly 6-8 general credits about religious and ethical issues.

2.2. Sampling and Sample Size. The sample size was estimated to be 300 in each group by using the mean difference formula. Regarding the probability of dropout in each university, 330 questionnaires were provided to the students by using a convenience sampling method. 313 questionnaires were fully delivered from the University of Medical Sciences $(n=4556)$ and 313 from Shahid Bahonar University of Kerman $(n=14,533)$, and ultimately, they were included in the software (response rate 94.85).
2.3. Instrument. The demographic characteristics form and the spiritual well-being scale developed by Palutzian \& Ellison were used to measure the spiritual well-being of the students. The first part of the survey was related to the demographic data of the participants, including age, gender, marital status of the parents, occupation, education, field of study, an academic semester, university name, and living place. The 20-item spiritual well-being scale of Palutzian \& Ellison [15] was used to measure the students' spiritual wellbeing, which consists of two subscales of religious well-being and existential well-being. The students were asked about the extent of their spiritual well-being on a six-point Likert scale, ranging from 1 (strongly disagree) to 6 (strongly agree). The score for spiritual well-being was the sum of the two subscales ranging from 20 to 120 . The scores of 20-40 show low, 41-99 show moderate, and 100-120 show high spiritual wellbeing. The Persian version of the scale was tested for validity and reliability, and its validity and reliability have been confirmed (alpha coefficient $=0.85)$ [16].

2.4. Data Collection and Analysis. The researcher referred to research settings after obtaining the code of ethics and presented a written letter to the university's management. The researchers referred to libraries, study halls, student dormitories, and classes at Shahid Bahonar University and the University of Medical Sciences in Kerman in the morning and afternoon. The students completed and delivered the self-report questionnaires. The inclusion criteria were students of universities of Shahid Bahonar and Medical Sciences, who were willing to participate in this study. Guest students and incomplete questionnaires were excluded from the study.

Data were analyzed with SPSS version 25. Frequency, percentage, mean, and standard deviation were used to describe the studied variables. The independent $t$-test was used for the spiritual well-being score between the two groups. Independent $t$-test ANOVA, the Mann-Whitney $U$, and Kruskal-Wallis tests were used to compare the spiritual well-being score regarding demographic variables in each group. The significance level considered $<0.05$.

2.5. Ethical Consideration. The Kerman University of Medical Sciences approved this project (IR.KMU.REC.1396.1798). Then, permission was issued to the management of the two universities. Some oral information was given to the participants, including the goals and objectives of the study and the confidentiality and anonymity of the data, and that they were free to withdraw from the study at any time. Informed consent was obtained from all individual participants included in the study.

\section{Results}

3.1. Sociodemographic Characteristics. Six hundred and twenty-six students (313 nonmedical science and 313 medical science students of Kerman universities) participated in this study. The mean ages of nonhedical science and medical science students were $20.87 \pm 3.62$ and $21.81 \pm 4.03$, 
respectively. 61 percent of the nonmedical science students and 73.8 percent of the medical science students were females, and 88.2 percent of the medical science students and 88.7 percent of the nonmedical science students were single. In addition, $11.8 \%$ of the nonmedical science and medical science students were employed, and $99.7 \%$ of the nonmedical science students and $68.4 \%$ of the medical science students had associate and bachelor's degrees (Table 1).

\subsection{The Comparison of Spiritual Well-Being between Medical} and Nonmedical Science Students. The mean spiritual wellbeing of the nonmedical science students was $89.83 \pm 16.79$, and it was $81.61 \pm 15.21$ in the medical science students. A significant difference was observed between nonmedical science and medical science students in the scores of spiritual well-being and its two components, and the spiritual well-being of the nonmedical science students was higher than that of the medical science students. Furthermore, 1\% of the nonmedical science students $(n=3)$ had a low level, $67.7 \%(n=212)$ had a moderate level, and $31.3 \%(n=98)$ had a high level of spiritual well-being. $0.3 \%$ of the medical science students $(n=1)$ had a low level, $84 \%(n=263)$ had a moderate level, and $15.7 \%(n=49)$ had a high level of spiritual well-being (Table 2).

\subsection{The Spiritual Well-Being according to Sociodemographic} Subcategories of Students. There was no correlation between age and spiritual health $(r=0.08, p=0.87)$. In addition, females had higher spiritual health than males. A significant association was observed between spiritual well-being and academic year, and junior students had significantly higher spiritual health than the first year $(p=0.007)$, the $\geq$ fifth year $(p=0.04)$. In medical science university students, no correlation was found between age and spiritual health $(r=0.02$, $p=0.73)$. Students who were in the third and fourth years of their educational years had higher spiritual health than students who were in the first and second years of their education $(p=0.001)$. In nonmedical science universities, no correlation was found between age and spiritual health $(r=0.02, p=0.72)$. Also, females had higher spiritual health than males. In nonmedical sciences universities, no association was found between spiritual well-being and educational year (Table 3).

\section{Discussion}

The mean spiritual well-being of the nonmedical science students was $89.83 \pm 16.79$, and that of medical students was $81.61 \pm 15.21$, which was consistent with the results of Febbris et al. [5]. They acknowledged that students in this phase of their lives had to cope with this new situation, so spirituality could be an important coping strategy and protect against insecurity [5]. Feizi et al. in Iran also showed a moderate amount of spiritual well-being of students. Owing to the fact that spirituality and spiritual values have a special place in Islam and help individuals achieve inner peace and increase their ability to effectively manage stress, such findings are somewhat expected for Iranian people [11].
Spiritual well-being and its dimensions (existential wellbeing and religious well-being) were significantly higher in the nonmedical science students than the medical science students. In the present study, the difference between medical and nonmedical students about spiritual well-being could be clinically significant as it is obvious by the amount of effect size, i.e., 51. These results were consistent with the results of Yang et al. [17] and inconsistent with the results of Al-Qahtani. Their results showed better health responsibility and spiritual growth in the medical students than the nonmedical group and said it is necessary to introduce a well-being and health curriculum and a culture that promotes spiritual well-being [3]. Joys and Yanzom and Tapley et al. [18] revealed no significant difference between medical and nonmedical professional students in spiritual growth [19]. The gender differences with religious and cultural factors may be the reason for different results.

The results showed that the nonmedical science female students had more spiritual well-being than the male students, which was supported by Joys and Yanzom [19]. These results may be due to different social customs, life experiences, coping strategies, the various roles and characteristics of women, and their greater consistency with the spiritual principles. However, this difference was not observed among medical science students. These results were consistent with the results of Haghighat and Koolaee [20], who found no significant difference in spiritual well-being among male and female nurses. They believed that the spiritual well-being of the nurses caring for patients in medical wards was one of the effective psychological variables and special attention should be paid to spiritual well-being in the education of nurses. However, these results were inconsistent with the results of Tavan et al. [21], Rahimi et al. [6], and Ziapour et al. [22]. They demonstrated that the roles, characteristics, and behaviors socially attributed to women might be more consistent with some of the religious and spiritual principles and norms.

In this study, the spiritual well-being of married and single individuals was not different among medical and nonmedical science students which is consistent with the studies of Rahimi et al. (2014) [6] and Papazisis et al. [10] and inconsistent with the results of Tavan et al. (2015) [21] and Najarkolae et al. [7]. Furthermore, Soleimani et al. [23] concluded that singleness was associated with less spiritual well-being compared with marriage. They argued that spirituality was a critical and positive component in marital life, and people with high spiritual well-being were more committed to their spouses and considered such a commitment as a spiritual purpose.

The results of this study showed that the spiritual wellbeing of the medical and nonmedical students was not different regarding location, which was not supported by Tavan et al. [24]. They noticed that total spiritual well-being scores of nursing students not living in dormitories were higher than those of the students living in dormitories because they were living with their parents and did not experience problems of being away from home and family promoted spirituality in students.

The results of this study showed that the third-year medical science students had higher spiritual well-being 
TABLE 1: Sociodemographic characteristics of the sample $(n=626)$.

\begin{tabular}{|c|c|c|c|c|}
\hline \multirow{2}{*}{ Variable } & \multicolumn{2}{|c|}{ Medical science students } & \multicolumn{2}{|c|}{ Nonmedical science students } \\
\hline & Mean & SD & Mean & SD \\
\hline Age (yr.) & 20.87 & 3.62 & 21.81 & 4.03 \\
\hline Variable & Frequency & Valid percent & Frequency & Valid percent \\
\hline \multicolumn{5}{|l|}{ Educational year } \\
\hline First & 122 & 39 & 103 & 32.9 \\
\hline Second & 83 & 26.5 & 92 & 29.4 \\
\hline Third & 54 & 17.3 & 62 & 19.8 \\
\hline Forth & 29 & 9.3 & 31 & 9.9 \\
\hline Fifth and upper & 25 & 8 & 25 & 8 \\
\hline \multicolumn{5}{|l|}{ Sex } \\
\hline Female & 189 & 61 & 231 & 73.8 \\
\hline Male & 121 & 39 & 82 & 26.2 \\
\hline \multicolumn{5}{|l|}{ Marital status } \\
\hline Single & 272 & 87.7 & 272 & 87.2 \\
\hline Married & 38 & 12.3 & 40 & 12.8 \\
\hline \multicolumn{5}{|l|}{ Occupation } \\
\hline Unemployed & 276 & 88.2 & 269 & 88.2 \\
\hline Employed & 37 & 11.8 & 36 & 11.8 \\
\hline \multicolumn{5}{|l|}{ Living with both parents } \\
\hline Yes $^{\circ}$ & 280 & 90.3 & 282 & 93.4 \\
\hline No & 30 & 9.6 & 20 & 6.6 \\
\hline \multicolumn{5}{|l|}{ Educational grade } \\
\hline Bachelor's degree & 312 & 99.7 & 214 & 68.4 \\
\hline Master's degree/professional doctorate & 1 & 0.3 & 99 & 31.6 \\
\hline \multicolumn{5}{|l|}{ Major } \\
\hline Medical science & 3 & 1 & 313 & 100 \\
\hline Nonmedical science & 310 & 99 & 0 & 0 \\
\hline \multicolumn{5}{|l|}{ Living place } \\
\hline Student dormitory & 115 & 38.2 & 204 & 65.4 \\
\hline Rented house & 26 & 8.6 & 13 & 4.2 \\
\hline Resident of Kerman & 160 & 53.2 & 95 & 30.4 \\
\hline
\end{tabular}

In cases that the frequency was less than 313 , there were missing values.

TABLE 2: Comparison of scores of spiritual well-being and its dimensions among nonmedical and medical science students.

\begin{tabular}{|c|c|c|c|c|c|c|c|}
\hline \multirow[t]{2}{*}{ Variable } & \multicolumn{2}{|c|}{$\begin{array}{c}\text { Nonmedical } \\
\text { science students }\end{array}$} & \multicolumn{2}{|c|}{$\begin{array}{l}\text { Medical science } \\
\text { students }\end{array}$} & \multirow[t]{2}{*}{ Independent $t$-test } & \multirow[t]{2}{*}{$p$ value } & \multirow[t]{2}{*}{ Effect size } \\
\hline & Mean & SD & Mean & SD & & & \\
\hline Spiritual well-being & 89.83 & 16.79 & 81.61 & 15.21 & 6.42 & $<0.001$ & 0.51 \\
\hline Religious well-being & 48.10 & 9.34 & 42.08 & 8.21 & 8.59 & $<0.001$ & 0.68 \\
\hline Existential well-being & 41.71 & 9.36 & 39.49 & 7.90 & 3.20 & 0.01 & 0.26 \\
\hline
\end{tabular}

than others, which supported the results of Al-Qahtani [3] and did not support the results of Rahimi et al. [6]. However, this difference was only observed in medical science students and was not observed among nonmedical science students. Farahaninia et al. found that by understanding the patient's spiritual care along with physical care, medical science students would clinically enjoy greater spiritual well-being and perform medical and nursing care and also there was a real relationship between spiritual care and inner spirituality, meaning that the stronger and higher the inner spirituality of the nurse, the more often he/she will try to provide spiritual care to the patient [25].

The results also showed no significant relationship between age and spiritual well-being among medical and nonmedical science students, which was inconsistent with the studies of Rahimi et al. [6] and Tavan et al. [21]. Ziapour et al. [22] revealed that the mean scores of spiritual wellbeing were significantly different in various ages, and the older the age, the higher the students' spiritual well-being. Yuen believed that spirituality had a direct relationship with aging when encountering the reality of death and getting adapted to it [26]. Differences in the value and atmosphere of spirituality in the studied cities may be the reasons for the contradiction of the studies mentioned above.

In this study, self-reporting was used to collect data, so students might not provide accurate information. There are limitations in terms of generalizations, interpretations, and etymological variables because of students' cognitive, social, and familial differences. Therefore, it is suggested that further research be conducted on statistical populations with 
TABLE 3: Scores of spiritual well-being regarding demographic variables of students.

\begin{tabular}{|c|c|c|c|c|c|c|c|c|c|}
\hline \multirow[t]{2}{*}{ Variable } & \multicolumn{2}{|c|}{$\begin{array}{l}\text { Spiritual } \\
\text { well-being } \\
\text { (total } \\
\text { sample) }\end{array}$} & \multirow[t]{2}{*}{$\begin{array}{l}\text { Statistical test } \\
\text { and } p \text { value }\end{array}$} & \multicolumn{2}{|c|}{$\begin{array}{c}\text { Spiritual } \\
\text { well-being } \\
\text { (nonmedical } \\
\text { science } \\
\text { students) }\end{array}$} & \multirow[t]{2}{*}{ Statistical test $\& p$ value } & \multicolumn{2}{|c|}{$\begin{array}{l}\text { Spiritual } \\
\text { well-being } \\
\text { (medical } \\
\text { science } \\
\text { students) }\end{array}$} & \multirow[t]{2}{*}{$\begin{array}{l}\text { Statistical test } \\
\text { and } p \text { value }\end{array}$} \\
\hline & Mean & SD & & Mean & SD & & Mean & SD & \\
\hline \multicolumn{10}{|l|}{ Educational year } \\
\hline First & 84.03 & 15.45 & \multirow{5}{*}{$H=13.36 p=0.01$} & 89.51 & 16.10 & \multirow{5}{*}{$F=1.14 p=0.34$} & 77.53 & 11.76 & \multirow{5}{*}{$H=24.29 p<0.001$} \\
\hline Second & 85.19 & 16.02 & & 91.61 & 16.37 & & 79.39 & 13.32 & \\
\hline Third & 90.44 & 18.52 & & 91.67 & 18.02 & & 89.37 & 19.02 & \\
\hline Forth & 87.22 & 17.71 & & 86.52 & 18.55 & & 87.87 & 17.16 & \\
\hline $\begin{array}{l}\text { Fifth and upper } \\
\text { Sex }\end{array}$ & 82.44 & 14.76 & & 85.32 & 16.47 & & 79.56 & 12.50 & \\
\hline Female & 86.85 & 15.86 & $t=2.43$ & 92.52 & 15.22 & $t=3.48$ & 82.21 & 14.87 & $t=1.18$ \\
\hline Male & 83.42 & 17.74 & $p=0.01$ & 85.80 & 18.46 & $p=0.001$ & 79.91 & 16.10 & $p=0.24$ \\
\hline \multicolumn{10}{|l|}{ Marital status } \\
\hline Single & 85.39 & 16.72 & $t=-1.37$ & 89.40 & 17.22 & $t=-1.22$ & 81.38 & 15.21 & $t=-0.83$ \\
\hline Married & 88.13 & 15.21 & $p=0.17$ & 92.97 & 13.70 & $p=0.22$ & 83.52 & 15.29 & $p=0.41$ \\
\hline \multicolumn{10}{|l|}{ Occupation } \\
\hline Unemployed & 85.53 & 16.73 & $t=-1.48$ & 89.41 & 17.22 & $Z=-1.13$ & 81.56 & 15.26 & $t=-0.93$ \\
\hline Employed & 88.57 & 14.85 & $p=0.14$ & 92.95 & 12.96 & $p=0.26$ & 84.08 & 15.49 & $p=0.35$ \\
\hline \multicolumn{10}{|c|}{ Living with both parents } \\
\hline Yes & 85.74 & 16.72 & $t=0.45$ & 89.85 & 16.49 & $t=0.45$ & 81.67 & 15.49 & $Z=-0.24$ \\
\hline No & 84.64 & 13.71 & $p=0.45$ & 88.40 & 15.46 & $p=0.65$ & 79.0 & 7.99 & $p=0.67$ \\
\hline \multicolumn{10}{|l|}{ Living place } \\
\hline Student dormitory & 84.55 & 16.64 & & 90.83 & 16.89 & & 81.02 & 15.45 & \\
\hline Rented house & 86.18 & 20.28 & $\begin{array}{l}F=1.70 \\
h-0.18\end{array}$ & 90.35 & 21.54 & $F=0.30$ & 77.85 & 14.92 & $\begin{array}{l}F=1.30 \\
h-0.30\end{array}$ \\
\hline Resident of Kerman & 15.86 & 0.10 & $p=0.18$ & 89.24 & 16.18 & & 83.52 & 14.69 & \\
\hline
\end{tabular}

$t=$ independent $t$-test, $F=$ analysis of variance, $Z=$ Mann-Whitney $U$ test, $H=$ Kruskal-Wallis.

other sociofamilial situations. In addition, the students' disciplines at the Shahid Bahonar University were very diverse; however, only $2 \%(n=6)$ of them were studying Quranic sciences disciplines. Therefore, it is suggested that further research be conducted on students with different religious studies disciplines.

\section{Conclusion}

The results showed a statistically significant difference between medical and nonmedical science students in the scores of spiritual well-being and its two components, and the spiritual well-being of the nonmedical science students was higher than that of the medical sciences ones. It can be concluded that paying attention to young people's demographic characteristics, such as gender, marital status, housing status, and university type, can be useful in the enhancement of spiritual well-being because spirituality is important for the profession of medical science students, so educational programs may be necessary to expand this component in their curriculum. Regarding the lack of research on factors predicting spiritual well-being in the youth group, especially students, it is suggested that this issue be investigated in other provinces for the promotion of spiritual well-being.

\section{Data Availability}

Data are available upon request to the corresponding author via email.

\section{Conflicts of Interest}

The authors declare that they have no conflicts of interest.

\section{Authors' Contributions}

All authors have seen and approved the content and have contributed significantly to the work and acknowledge that all those entitled to authorship are listed as authors. All authors made substantial contributions to the conception and design of the study, acquisition of data, analysis and interpretation of data, drafting the article or revising it critically for important intellectual content, and final approval of the version to be submitted.

\section{Acknowledgments}

The authors thank all the students for their sincere cooperation in this study.

\section{References}

[1] A. Duffy, K. E. A. Saunders, G. S. Malhi et al., "Mental health care for university students: a way forward?" The Lancet Psychiatry, vol. 6, no. 11, pp. 885-887, 2019.

[2] M. Asadi, N. S. Rezaie, and M. Miri, "The relationship between religiosity and demography factors with violence and highrisk sexual behavior among university students," Women and Study of Family, vol. 3, 2011. 
[3] M. F. Al-Qahtani, "Comparison of health-promoting lifestyle behaviours between female students majoring in healthcare and non-healthcare fields in KSA," Journal of Taibah University Medical Sciences, vol. 14, no. 6, pp. 508-514, 2019.

[4] M. D. Mathad, S. K. Rajesh, and B. Pradhan, "Spiritual wellbeing and its relationship with mindfulness, self-compassion and satisfaction with life in baccalaureate nursing students: a correlation study," Journal of Religion and Health, vol. 58, no. 2, pp. 554-565, 2019.

[5] J. L. Fabbris, A. C. Mesquita, S. Caldeira, A. M. P. Carvalho, and E. C. d. Carvalho, "Anxiety and spiritual well-being in nursing students: a cross-sectional study," Journal of Holistic Nursing, vol. 35, no. 3, pp. 261-270, 2017.

[6] N. Rahimi, E. Nouhi, and N. Nakhaee, "Spiritual health among nursing and midwifery students at Kerman university of medical sciences," Journal of Hayat, vol. 19, no. 4, pp. 74-81, 2014.

[7] F. R. Najarkolaei, M. Haghighi, A. B. Heydarabadi, A. Ansarian, and M. Mesri, "Investigation of spiritual health in staff of one medical sciences university in tehran," Journal of Pizhūhish Dar Dīn Va Salāmat, vol. 1, no. 1, pp. 13-20, 2015.

[8] O. I. Alorani and M. T. F. Alradaydeh, "Depression, aggression and spiritual well-being among the university students in Jordan," European Scientific Journal, ESJ, vol. 13, no. 2, pp. 269-280, 2017.

[9] O. I. Alorani and M. T. F. Alradaydeh, "Spiritual well-being, perceived social support, and life satisfaction among university students," International Journal of Adolescence and Youth, vol. 23, no. 3, pp. 291-298, 2018.

[10] G. Papazisis, P. Nicolaou, E. Tsiga, T. Christoforou, and D. Sapountzi-Krepia, "Religious and spiritual beliefs, selfesteem, anxiety, and depression among nursing students," Nursing \& Health Sciences, vol. 16, no. 2, pp. 232-238, 2014.

[11] S. Feizi, M. Nasiri, H. Bahadori, M. H. Amiri, and H. Mirhosseini, "The relationship between spiritual well-being and happiness among healthcare students: application of the spiritual health questionnaire for the Iranian population," Heliyon, vol. 6, no. 11, Article ID e05448, 2020.

[12] A. Mehri, M. Solhi, G. Garmaroudi, H. Nadrian, and S. S. Sighaldeh, "Health promoting lifestyle and its determinants among university students in Sabzevar, Iran," International Journal of Preventive Medicine, vol. 7, p. 65, 2016.

[13] A. Musa, "Spiritual beliefs and practices, religiosity, and spiritual well-being among Jordanian Arab muslim university students in Jordan," Journal of Spirituality in Mental Health, vol. 17, no. 1, pp. 34-49, 2015.

[14] A. M. Abdel-Khalek, "Quality of life, subjective well-being, and religiosity in muslim college students," Quality of Life Research, vol. 19, no. 8, pp. 1133-1143, 2010.

[15] R. F. Paloutzian and C. W. Ellison, "Loneliness, spiritual wellbeing and the quality of life," in Loneliness: A Sourcebook of Current Theory, Research and TherapyWiley, Hoboken, NJ, USA, 1982.

[16] M. B. Abhari, J. W. Fisher, A. Kheiltash, and M. Nojomi, "Validation of the Persian version of spiritual well-being questionnaires," Iranian Journal of Medical Sciences, vol. 43, no. 3, p. 276, 2018.

[17] W. Yang, T. Sim, K. Cui, J. Zhang, Y. Yang, and X. Ma, "Health-promoting lifestyles among health care workers in a postdisaster area: a cross-sectional study," Disaster Medicine and Public Health Preparedness, vol. 13, no. 02, pp. 230-235, 2019.

[18] H. Tapley, D. Fell, and D. Pitts, "Exploration of spirituality in doctor of physical therapy students and graduate students in non-health disciplines," International Journal of Therapy and Rehabilitation, vol. 19, no. 10, pp. 566-574, 2012.

[19] B. Joys and D. Yanzom, "Health promoting lifestyle practices: a comparative study on health and non-health professional students," Indian Journal of Public Health Research \& Development, vol. 10, no. 7, 2019.

[20] K. R. Haghighat and A. K. Koolaee, "Comparison of spiritual intelligence and self-regulation of male and female nurses in intensive/general wards of hospitals in Tehran city," Journal of Reaserch on Religion \& Health, vol. 2, no. 1, pp. 3-10, 2016.

[21] H. Tavan, H. Taghinejad, K. Sayehmiri et al., "Spiritual health of nursing students," Islam and Health Journal, vol. 2, no. 1, pp. 26-32, 2015, (in Persian).

[22] A. Ziapour, A. Khatony, F. Jafari, and N. Kianipour, "Prediction of the dimensions of the spiritual well-being of students at Kermanshah university of medical sciences, Iran: the roles of demographic variables," Journal of Clinical and Diagnostic Research: JCDR, vol. 11, no. 7, p. VC05, 2017.

[23] M. A. Soleimani, S. P. Sharif, A. Yaghoobzadeh, M. R. Sheikhi, B. Panarello, and M. T. M. Win, "Spiritual well-being and moral distress among Iranian nurses," Nursing Ethics, vol. 26, no. 4, pp. 1101-1113, 2019.

[24] H. Tavan, H. Taghinejad, S. R. Mousavi Moghadam, K. Sayehmiri, and I. Mohammadi, "A comparison of spiritual health of male and female students in the Ilam university of medical sciences," Journal of Paramedical Sciences (JPS), vol. 6, no. 2, pp. 19-25, 2015.

[25] M. Farahaninia, M. Abbasi, A. Givari, and H. Haghani, "Nursing students' spiritual well-being and their perspectives towards spirituality and spiritual care perspectives," Iran Journal of Nursing and midwifery Research, vol. 18, no. 44, pp. 7-14, 2006, (in Persian).

[26] C. Y. M. Yuen, "Gender differences in life satisfaction and spiritual health among the junior immigrant and local Hong Kong secondary students," International Journal of Children's Spirituality, vol. 20, no. 2, pp. 139-154, 2015. 